Section Editor

John J. Millichap, MD

Dr. Kurowski:

Donna.kurowski@uphs.upenn.edu

Pearls \& Oy-sters:

\title{
Iatrogenic relative hypotension leading to diffuse internal borderzone infarctions and coma
}

\section{PEARLS}

- Isolated hypoperfusion is more likely to cause internal borderzone infarcts and less likely to cause cortical borderzone infarcts.

- Cortical borderzone infarction should raise suspicion for an embolic etiology.

- Diffuse subcortical infarcts from hypoperfusion can lead to poor neurologic outcome.

\section{OY-STER}

- Patients who present with severe hypertension should have their blood pressure initially lowered by no more than $25 \%$ to reduce the chance of cerebral, coronary, or renal ischemia.

CASE REPORTS We present 2 patients with hypertensive emergency who developed extensive watershed infarcts after their blood pressure was rapidly lowered.

The first patient was a 50-year-old man admitted to an outside hospital with shortness of breath and an initial blood pressure of 204/108 mm Hg. He was diagnosed with hypertensive emergency and started on IV nicardipine drip, which dropped his blood pressure to $102 / 66 \mathrm{~mm} \mathrm{Hg}$ within a few minutes. His blood pressure remained in this range for 2 hours, and he became unarousable. Attempts were made to increase his blood pressure with fluids though his level of consciousness did not improve. MRI diffusion-weighted imaging (DWI) subsequently revealed numerous infarcts in the bilateral internal borderzone (IBZ) (figure, A). Vascular imaging revealed intracranial atherosclerosis with moderate narrowing of multiple arteries. He was transferred to our hospital for further care, and remained in a vegetative state until discharge on hospital day 74 .

The second patient was a 41-year-old man who presented to the hospital with chest pain and was found to have a descending aortic dissection with a blood pressure of 235/144 mm Hg. An IV nicardipine drip was initiated to prevent extension of the dissection, and the patient became unarousable when the blood pressure dropped to $114 / 52 \mathrm{~mm} \mathrm{Hg}$, where it remained for approximately 3 hours. Subsequent MRI DWI revealed numerous foci of IBZ and corpus callosum infarctions, seen in the figure, B. Carotid ultrasound studies did not reveal any significant stenosis in the external or internal carotid arteries. Follow-up imaging performed 2 months after the initial imaging showed the expected evolution of the known infarcts with no new infarcts noted. The patient died on hospital day 86 without regaining consciousness.

DISCUSSION Watershed strokes comprise approximately $10 \%$ of all ischemic strokes and are characterized by infarction localized to the borderzones between major vascular territories in the brain. ${ }^{1}$ Watershed strokes can occur in the IBZ or cortical borderzone (CBZ), seen in the figure, $\mathrm{C}$. The cortical borderzones are located at the junctions of the distal branches of the anterior, middle, and posterior cerebral artery territories. Internal borderzones are located at the junctions of the distal branches of the anterior, middle, and posterior cerebral artery territories with the deep perforating arteries, including the lenticulostriate arteries, artery of Heubner, and the anterior choroidal artery. There is accumulated evidence that the distinct patterns of IBC and CBZ infarcts may shed light on the underlying mechanism of injury. Specifically, IBZ infarcts are more likely to be caused by isolated perfusion failure while CBZ infarcts are more likely due to thromboembolism with impaired washout, or clearance, of emboli in these relatively low-flow areas. ${ }^{2,3}$

These 2 cases help illustrate the association between the presence of IBZ infarcts and hemodynamic compromise. From a series of 120 patients with watershed infarcts, IBZ infarcts are more often associated with severe stenosis or occlusion in the ICA or MCA while CBZ infarcts are more often associated with other small cortical infarcts suggestive of embolism. ${ }^{2}$ Similarly, a study of patients with carotid disease demonstrated that small embolic lesions on DWI are associated with a lower degree of ICA stenosis while patients with a higher degree of stenosis have fewer microembolic

From the Department of Neurology, Hospital of the University of Pennsylvania, Philadelphia.

Go to Neurology.org for full disclosures. Funding information and disclosures deemed relevant by the authors, if any, are provided at the end of the article. 
Figure

(A) MRI diffusion-weighted imaging (DWI) sequence from the first case, (B) MRI DWI sequence from the second case, and (C) cortical borderzones in red and internal borderzones in blue

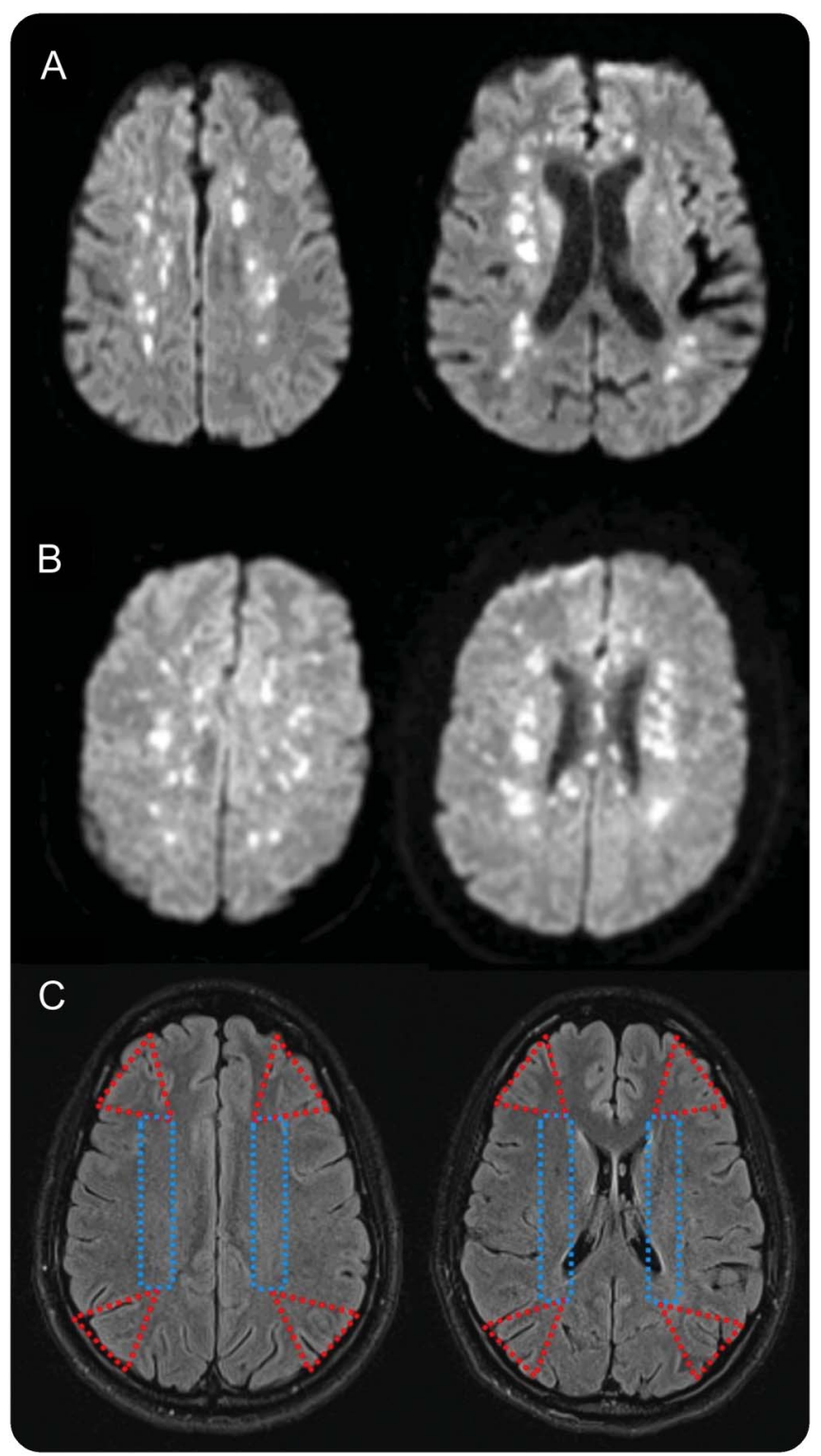

signals (MES) detected with transcranial Doppler imaging. ${ }^{4}$ This is in contrast to another series of patients with carotid stenosis, where MES were seen in patients with and without IBZ infarcts, suggesting that microembolism may play a role for some patients, particularly in the setting of hemodynamic impairment. ${ }^{5}$ The IBZ is thought to be more vulnerable to decreased cerebral perfusion due to the anatomic characteristics of cerebral arterioles within this area. These vessels are the most distal branches of the ICA, where perfusion pressure is likely to be the lowest. ${ }^{6}$ In addition, lenticulostriate arteries have limited collateral blood supply. Finally, as with these 2 cases, patients with extensive IBZ infarcts are at risk for prolonged hospitalization and have a higher likelihood of long-term disability than patients with CBZ infarcts. ${ }^{2}$
In contrast to the IBZ, the CBZ is adjacent to the cortical surface, where leptomeningeal and dural anastomoses provide collateral blood supply, making the CBZ more resistant to direct injury from decreased cerebral perfusion. ${ }^{7}$ Additional evidence that $\mathrm{CBZ}$ infarcts are more likely to be caused by an embolic etiology comes from a recent study of patients undergoing transcatheter atrial fibrillation ablation. ${ }^{8}$ In this study, 78 of 927 $(8.4 \%)$ consecutive patients who underwent ablation were found to have acute silent cerebral infarcts on postoperative MRI. These silent periprocedural infarcts were much more frequently located in the $\mathrm{CBZ}$ than the IBZ, consistent with the notion that emboli are more likely to cause injury in these locations.

These cases illustrate 2 key points. First, in patients with severe hypertension, a rapid and dramatic blood pressure reduction can cause cerebral hypoperfusion and coma, even without frank hypotension. Patients who present with severe hypertension should have their blood pressure lowered initially by no more than $25 \%$ to reduce the chance of cerebral, coronary, or renal ischemia. ${ }^{9}$ Current guidelines for acute aortic dissection management recommend targeting a systolic blood pressure of $100-120 \mathrm{~mm} \mathrm{H}_{2} \mathrm{O} \cdot{ }^{10}$ In this setting, an initial rapid reduction in blood pressure of $25 \%$, followed by additional incremental reductions over a short amount of time to reach the target blood pressure, is advisable. In addition, serial neurologic assessments should be performed to identify ischemia and take steps to increase brain perfusion if needed. Finally, the pattern of watershed infarcts may shed light on the underlying stroke mechanism. While these findings are by no means pathognomic, it appears that IBZ infarcts are more likely to be related to hypoperfusion, while CBZ infarcts should raise suspicion for an embolic etiology.

\section{AUTHOR CONTRIBUTIONS}

Donna Kurowski: study concept and design, acquisition of data, author of manuscript. Michael T. Mullen: study concept and design, critical revision of manuscript for intellectual content. Steven R. Messé: study concept and design, critical revision of manuscript for intellectual content.

\section{STUDY FUNDING}

No targeted funding reported.

\section{DISCLOSURE}

The authors report no disclosures relevant to the manuscript. Go to Neurology.org for full disclosures.

\section{REFERENCES}

1. Torvik A. The pathogenesis of watershed infarcts in the brain. Stroke 1984;15:221-223.

2. Yong SW, Bang OY, Lee PH, Li WY. Internal and cortical border-zone infarction: clinical and diffusion-weighted imaging features. Stroke 2006;37:841-846.

3. Mangla R, Kolar B, Almast J, Ekholm SE. Border zone infarcts: pathophysiologic and imaging characteristics. Radiographics 2011;31:1201-1214. 
4. Szabo K, Kern R, Gass A, Hirsch J, Hennerici M. Acute stroke patterns in patients with internal carotid artery disease: a diffusion-weighted magnetic resonance imaging study. Stroke 2001; 32:1323-1329.

5. Moustafa RR, Momjian-Mayor I, Jones PS, et al. Microembolism versus hemodynamic impairment in rosary-like deep watershed infarcts: a combined positron emission tomography and transcranial Doppler study. Stroke 2011; 42:3138-3143.

6. Yamauchi H, Fukuyama H, Kimura J, Konishi J, Kameyama M. Hemodynamics in internal carotid artery occlusion examined by positron emission tomography. Stroke 1990;21:1400-1406.

7. Isaka $Y$, Nagano K, Narita M, Ashida K, Imaizumi M. High signal intensity on $\mathrm{T} 2$-weighted magnetic resonance imaging and cerebral hemodynamic reserve in carotid occlusive disease. Stroke 1997;28:354-357.
8. Bergui M, Castagno D, D'Agata F, et al. Selective vulnerability of cortical border zone to microembolic infarct. Stroke 2015;46:1864-1869.

9. Marik PE, Varon J. Hypertensive crises: challenges and management. Chest 2007;131:1949-1962.

10. Hiratzka LF, Bakris GL, Beckman JA, et al. 2010 ACCF/AHA/AATS/ACR/ASA/SCA/SCAI/SIR/STS/SVM Guidelines for the diagnosis and management of patients with thoracic aortic disease: a report of the American College of Cardiology Foundation/American Heart Association Task Force on Practice Guidelines, American Association for Thoracic Surgery, American College of Radiology, American Stroke Association, Society of Cardiovascular Anesthesiologists, Society for Cardiovascular Angiography and Interventions, Society of Interventional Radiology, Society of Thoracic Surgeons, and Society for Vascular Medicine. Circulation 2010;121:e266-e369. 


\section{Neurology}

\section{Pearls \& Oy-sters: Iatrogenic relative hypotension leading to diffuse internal borderzone infarctions and coma}

Donna Kurowski, Michael T. Mullen and Steven R. Messé

Neurology 2016;86;e245-e247

DOI 10.1212/WNL.0000000000002769

\section{This information is current as of June 13, 2016}

\section{Updated Information \& Services}

References

Subspecialty Collections

Permissions \& Licensing

Reprints including high resolution figures, can be found at: http://n.neurology.org/content/86/24/e245.full

This article cites 10 articles, 8 of which you can access for free at: http://n.neurology.org/content/86/24/e245.full\#ref-list-1

This article, along with others on similar topics, appears in the following collection(s):

All Cerebrovascular disease/Stroke

http://n.neurology.org/cgi/collection/all_cerebrovascular_disease_strok e

Coma

http://n.neurology.org/cgi/collection/coma

Critical care

http://n.neurology.org/cgi/collection/critical_care

DWI

http://n.neurology.org/cgi/collection/dwi

Infarction

http://n.neurology.org/cgi/collection/infarction

Information about reproducing this article in parts (figures,tables) or in its entirety can be found online at:

http://www.neurology.org/about/about_the_journal\#permissions

Information about ordering reprints can be found online:

http://n.neurology.org/subscribers/advertise

Neurology ${ }^{\circledR}$ is the official journal of the American Academy of Neurology. Published continuously since 1951, it is now a weekly with 48 issues per year. Copyright (O 2016 American Academy of Neurology. All rights reserved. Print ISSN: 0028-3878. Online ISSN: 1526-632X.

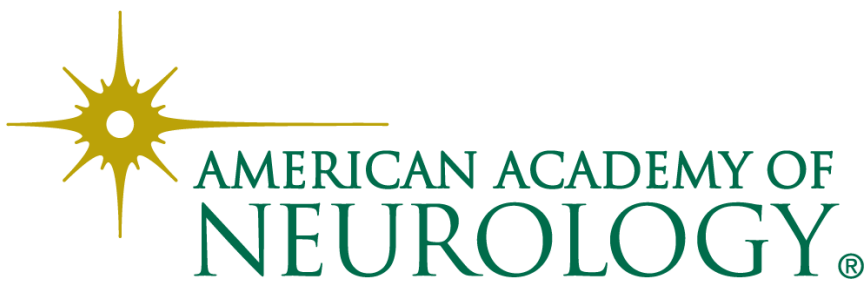

